\title{
The transformation of higher engineering education to meet the needs of manufacturing industry development
}

\author{
Wenhua Liu \\ The Institute of Higher Technical Education, Shanghai Dianji University, Shanghai, China \\ Iwhuajky@163.com
}

Keywords: manufacturing industry development; higher engineering education; transformation

\begin{abstract}
With the improvement and deepening of globalization, higher engineering education should adapt the requirement of manufacturing industry transformation. Nowadays, the development of higher engineering education paradigm in China gets the widespread recognition in the world. But the manufacturing industry and engineering technology raise new challenges, which need deeper reformation from the traditional science paradigm to modern engineering practical paradigm. This new change claims the transformation of talents cultivation mode of high engineering education.
\end{abstract}

\section{The background}

Manufacturing industry is the pillar of economic development, which represents the level of national economy. In recent years, although the proportion of internet economy and service industry in Gross Domestic Product is promoted dramatically in China, as to as the economic structure, the two kinds of industry will lose their development foundation if without the support of manufacturing industry. From the view of the whole world, Europe and America and other countries are carrying on the Strategy of Re-industrialization which blend in internet, artificial intelligence, digitization and other new technologies. Germany Industry 4.0 Is the presentation of the trend which is called the Fourth Industrial Revolution. The phenomenon also appears in other western developed countries. On this occasion, China begins to carry out new industry strategy: China Manufacture 2025. From the view of strategy implementation, the transformation development of manufacturing industry depends on the supports from engineering education and its' talents cultivation. So we should attach importance to engineering education.

\section{How higher engineering education adapt the development of manufacturing industry}

In consideration of the China Manufacture 2025 strategy, except for the transformation of traditional industry and strengthening competitive industries, the execution of Industry 4.0 which takes intelligent production as the symbol is the inevitable choice to exceed european and american countries for China's manufacturing industry in the future. Actually, Industry 4.0 and the China Manufacture 2025 strategy not only pursue the update of production technology and technology innovation of single production chain, but also the revolutionary transform of the collocation method of technology factors and production factors, and collaborative innovation of productive process, factors allocation, logistics process, data storage and else. Accordingly, in the process of industry production transformation from large scale production to intelligent production, the need of low-grade talents will decrease remarkably. At the meanwhile, the demand of innovation-type, complex and technical advanced talents will increase rapidly. Therefore, universities and colleges should pay attention to the China Manufacture 2025 strategy and Industry 4.0 so that to specifically figure out how to cultivate these kinds of talents.

At present, engineering education in many countries is still on the stage of scientific paradigm which attaches importance to systematic knowledge and scientific theories. Engineering education should return its nature and origin: engineering practice. The transformation and upgrade of manufacturing industry, the development of strategic emerging industry and intelligent production 
demand engineers being equipped with complex knowledge structure and the capabilities of creatively problem solving in the field of complicated engineering problems.

Accordingly, engineering education should break through single-discipline mindset and construct new engineering education paradigm which is based on entirety-engineering perspective, innovation perspective and environment perspective. This will help engineering education promote its standard and transformation.

In practice, the transformation of engineering education paradigm is a long-term and gradual reform process. And the transformation of engineering education paradigm cannot happen autonomously. Engineering education colleges should change and reform initiatively. The transformation of engineering education paradigm is a process of constructing new education paradigm which conform to the talents market demand of manufacturing industry.

\section{The transformation of higher engineering education in China}

The objective of China Industry 2025 is not the blocking development and recycling of traditional production mode. It is the open industry system which is based on innovation, intelligence and green. Accordingly, engineering education should step off the institutional defect of technical talents or academic talents cultivating. All these requirements depend on the open system of engineering education paradigm. The open system should include the factors as follows.

The first factor is the openness of programs and discipline. In the era of Industry 4.0 the connection between different industries and enterprises which are connected through internet and IOT will become frequent and intimate. This demands engineers being equipped with interdiscipline knowledge, learning capabilities and the capabilities of solving comprehensive engineering problems. Therefore, engineering education must break the blocks between different programs and disciplines and study interdiscipline knowledge. The blend beyond programs not only exists between engineering sciences but also among sciences, engineering, arts and humanities.

The second factor is the openness of talents cultivating institutions. The educational concept of Returning back to Engineering embodies the cooperative responsibility of multi-institution. The multi-institution includes government, manufacturing industry enterprises, universities, industry association and other stakeholders. In practice, these kinds of cooperative mechanism is multifaceted and multi-way cooperation between multiple organizations which devote to the construction of engineering education system. In terms of inter-university cooperation, different type and different level universities should construct multilevel and multitype talents cultivating structure which focuses on the innovation chain of manufacturing industry. In terms of university-enterprise cooperation, enterprises and industry should participate closely in the formulation of talents cultivating standards, programs development, internship base and other training platform of engineering education.

The third factor is the openness of cultivating mode. It means the primary teaching mode which takes theory teaching and classroom teaching as the principal thing and construct new teaching mode of experience engineering practice in real engineering circumstance. Modern engineering education has two characters: normalization and realization. The open cultivating mode can be divided to three types: experience mode, practice mode and innovation mode. Experience mode takes experiencing engineering theory knowledge and knowing engineering circumstance as the key objective. It includes engineering training centers, simulation factories and internship bases. Practice mode takes cultivating students engineering practice capabilities and solving engineering problems capabilities as the key objective. It includes CDIO (Conception, Design, Implementation, and Operation) engineering education mode, PBL (Problem-based Learning) teaching model, OBE (Outcome-based Education) teaching mode. While the key objective of innovation mode is cultivating student innovation thinking capabilities, innovating engineering technologies, master discipline front academic. It includes engineering innovation experiment which takes projects as the base, engineering innovation capability training which takes technology competition activities as the carriers. 


\section{The conclusion}

In consideration of the China Manufacture 2025 strategy and global competitive situation of manufacturing industry, the future development of manufacturing industry appeals to the all-around reform of engineering education. The demands for engineer talents are various, which not only includes engineer scientists who have broad knowledge structure and innovation capabilities but also excellent engineers who have fair practice capabilities and leadership and engineering technicians who have pretty operational capabilities. Accordingly different types of universities should choose different talent-cultivation object. Engineering universities focus on cultivating engineering technology innovation and industry creation. Comprehensive universities devote their mind to develop new technologies and foster new industry. Local colleges can play a role in support regional economic development and industry transformation and upgrade. The current key issue is not whether universities develop new engineering education and education reform. It is how to develop new engineering education and cultivate new engineering talents.

From the perspective of programs, universities should construct programs structure which copes with national strategic new industries and region dominant industries. Therefore, we should upgrade current programs and disciplines. This is the first thing we should do so as to serve the transformation and upgrade of traditional industries such as petrochemical industry, automobile, textile, steel and so on. Then new interdiscipline and programs should be set up according to the demand of national and regional manufacturing industry development which match strategic new industries and future technologies.

\section{References}

[1] Li Liguo, the talents cultivation mode of Higher Education in the era of Industry 4.0, Tsinghua University Education Research, 2016-37.

[2] Chen Xianyu, the Cold thinking on the upsurge of Industry 4.0: how to understand and carry out China Industry 2025 Strategy, Enterprise Management, 2015-7.

[3] Lv Zhengze, Zhang Wei, Li Tuoyu, the Strategies of Structure transformation of China's Engineering Education to cultivate System Engineers, Research on Higher Engineering Education, 2016-5.

[4] Li Maoguo, Zhu Zhengwei, the Paradigm of Engineering Education: From Returning to Engineering to Integration and Innovation, China Higher Education Research, 2017-6.

[5] Zhang Lidong, Research on the routine of transformation and upgrade of manufacturing industry under the background of China Manufacture 2025, Jiangxi Social Science, 2016-36. 